\title{
A Study of Variation in Adult Thrombocytopenic Histograms - A Graph Often Overlooked
}

\author{
Archana Shetty ${ }^{1}$, Shubha. H.V ${ }^{2 *}$, Vijaya Chowdappa ${ }^{2}$ and Vivek. T. G ${ }^{2}$ \\ ${ }^{1}$ Department of Pathology, Dr. Chandramma Dayanand Sagar Institute of Medical Education and Research, Harohalli, Ramanaga, India \\ ${ }^{2}$ Department of Pathology, Sapthagiri Institute of Medical Sciences and Research Centre, Bangalore, India
}

\begin{abstract}
Background: With the advent of automation in hematology, both platelet indices and their histograms are available from the blood cell counters at no extra cost or time. The variations of histograms in various mechanisms of thrombocytopenias are explored in this study.

Methods: Adults with thrombocytopenia determined with (name of the analyser)were categorized into four groups based on the mechanism of thrombocytopenia and variations in platelet histograms were studied in all groups. Data was collated and analysed using Microsoft Excel.

Results: A total of 224 adults with thrombocytopenia were seen, most of them had hyperdestructive type (73.6\%) followed by hypoproductive type (16.08\%), abnormal pooling (6.3\%) and EDTA induced thrombocytopenia (4.01\%). The following variations in histogram were seen; Normal curve( $8.03 \%)$, Curve not touching/reaching the baseline (43.75\%), Broad based curve (10.71\%), Bimodal curve $(7.14 \%)$, Curve with short peak $(25.9 \%)$ and Saw-tooth appearance of curve $(4.47 \%)$ and correlated with the above mentioned mechanisms of thrombocytopenias using SPSS software version 20.

Conclusion: An awareness regarding the variations in the platelet curve ensures a good correlation with its numerical parameters and also with the etiology of thrombocytopenias. With the era of automation taking over in most of the laboratories, it is imperative to have knowledge about these simple yet, often overlooked platelet histograms
\end{abstract}

\section{Keywords: Histograms, Thrombocytopenia, Bimodal Curve, Short Peak}

\section{Introduction}

Thrombocytopenia“(TCP);" a platelet count below $150 \times 10^{9} / \mathrm{L}$ is a common medical condition associated with a wide variety of diseases. ${ }^{[1]}$ During the evaluation of patients with thrombocytopenia, it is essential to understand the underlying mechanism of thrombocytopenia and classify the mechanism of thrombocytopaenia in to hyperdestruction, hypoproduction, abnormal platelet pooling or EDTA induced. This approach will narrow differentials, avoid unnecessary investigations and aid in targeted management. ${ }^{[2]}$

Manual methods for determination of hematological parameters in laboratories which are Manual methods for determination of hematological parameters in laboratories which are labor intensive and time consuming are now largely replaced by automated analyzers. These analyzers routinely give platelet histogram in addition to platelet count and indices at no extra cost. ${ }^{[3,4,5]}$ However, the histogram is often neglected, with the main emphasis being only on the platelet counts. ${ }^{[6]}$ A good basic knowledge on the interpretation of histograms can be a useful adjunct tool along with platelet indices to determine the underlying mechanism of thrombocytopaenia. This study was undertaken with an intention to study the alterations in platelet histograms and to correlate the same with the etiology of thrombocytopenias.

\section{Aims and Objectives}

1. To categorize the thrombocytopenic cases based on the underlying mechanism.

2. To study the variation in platelet histograms among the above categorized groups.

\section{Materials and Methods}

This cross sectional study was conducted in the hematology department of our institutional central laboratory over a period of three months from June to August 2019. A total of 224 patients aged 18 years and above of both the sexes with a platelet count of less than $150 \times 10^{9} / \mathrm{L}$ whose request form contains sufficient clinical details were included. EDTA anti-coagulated venous samples were run within four hours of sample collection with Sysmex XN-550 autoanalyzer for platelet counts \& histograms. A peripheral blood smear stained with Leishman's stain was also reviewed by the reporting pathologist with Olympus CX21i microscope, which also helped to rule out pseudothrombocytopenic cases. The analyzer was standardized daily by routine quality checks of repeatability and 
precision using standardised quality control material. Relevant clinical data (history of fever, drug intake etc.), demographic details, working diagnosis and supportive investigations along with serological test results of the cases relevant to the study (eg. dengue, typhidot and rapid malarial serology tests) were collected using the laboratory information system, maintaining the patients' anonymity. The cases were categorized into 4 groups based on the mechanisms of thrombocytopenia as follows: Group 1- Hyperdestructive thrombocytopenias , Group 2- Hypoproductive thrombocytopenias and Group 3thrombocytopenias due to abnormal pooling and Group 4 - EDTA induced thrombocytopenias caused due to antiplatelet antibodies of cold agglutinin type such as $\mathrm{IgG}$, IgM and IgA with the platelet surface antigens. Platelet histograms were studied in all the above mentioned cases. Prior institutional ethical committee clearance was taken for the study.

Statistical analysis: The data collected was entered in excel sheet and was analysed using the software Statistical Package for Social Sciences (SPSS) program version 20. Variations in platelet histograms were studied in the four etiological categories (hyperdestuctive, hypoproductive,abnormal pooling and EDTA induced thrombocytopenias) of thrombocytopenic groups.

\section{Results}

Among the 224 cases taken for the study, majority fell into the age group of 18-38 years (FIGURE 1). The male to female ratio was 1.3:1 (FIGURE 2).

Table 1: Table showing etiological distribution of cases.

\begin{tabular}{|l|c|}
\hline ETIOLOGIES OF THROMBOCYTOPENIA & PERCENTAGE \\
\hline HYPERDESTRUCTIVE & 73.6 \\
\hline HYPOPRODUCTIVE & 16.08 \\
\hline ABNORMAL POOLING & 4.02 \\
\hline EDTA-INDUCED THROMBOCYTOPENIA & 6.3 \\
\hline TOTAL & $\mathbf{1 0 0}$ \\
\hline
\end{tabular}

Table 2: Distribution of thrombocytopenic cases in each group.

\begin{tabular}{|c|c|c|c|}
\hline ETIOLOGIES & CAUSES & NO. OF CASES (\%) & TOTAL \\
\hline \multirow{7}{*}{$\begin{array}{l}\text { GROUP } \\
\text { A(HYPERDESTRUCTIVE) } \\
\text { CASES }\end{array}$} & Viral fevers (Dengue included) & 86 & \multirow[t]{7}{*}{$165(73.6 \%)$} \\
\hline & Sepsis & 26 & \\
\hline & Malaria & 9 & \\
\hline & Liver diseases & 18 & \\
\hline & Renal diseases & 14 & \\
\hline & Cardiac diseases & 08 & \\
\hline & ITP & 4 & \\
\hline \multirow{3}{*}{$\begin{array}{l}\text { GROUP B } \\
\text { (HYPOPRODUCTIVE) CASES }\end{array}$} & Anemias & 24 & \multirow[t]{3}{*}{$36(16.1 \%)$} \\
\hline & Leukemias/MDS & 8 & \\
\hline & Pancytopenias & 4 & \\
\hline $\begin{array}{l}\text { GROUP C (ABNORMAL } \\
\text { POOLING) CASES }\end{array}$ & Splenomegaly & 9 & $9(3.9 \%)$ \\
\hline $\begin{array}{l}\text { GROUP D (EDTA-INDUCED } \\
\text { THROMBOCYTOPENIA) CASES- }\end{array}$ & Antibodies & 14 & $14(6.4 \%)$ \\
\hline
\end{tabular}

Table 3: Table showing different patterns of platelet histograms in thrombocytopenic cases.

\begin{tabular}{|c|c|c|c|c|c|c|c|}
\hline \multirow[t]{2}{*}{ GROUPS } & \multicolumn{6}{|c|}{ PATTERNS OF PLATELET HISTOGRAMS* } & \multirow[t]{2}{*}{ TOTAL (\%) } \\
\hline & NC & NTB & BB & BM & SP & ST & \\
\hline GROUP A & 8 & 89 & 19 & 12 & 37 & 0 & $165(73.6 \%)$ \\
\hline GROUP B & 3 & 6 & 4 & 3 & 20 & 0 & $36(16.08 \%)$ \\
\hline GROUP C & 5 & 1 & 1 & 1 & 1 & 0 & $9(4.02 \%)$ \\
\hline GROUP D & 2 & 2 & 0 & 0 & 0 & 10 & $14(6.3 \%)$ \\
\hline TOTAL & $18(8.03 \%)$ & $98(43.75 \%)$ & 24 (10.71\%) & $16(7.14 \%)$ & $58(25.9 \%)$ & $10(4.47 \%)$ & $224(100 \%)$ \\
\hline
\end{tabular}

*NC-Normal curve, NBT-Curve not touching the baseline, BB-Broad base, BM-Bimodal, SP-Short peak, ST-Saw-tooth appearance. 


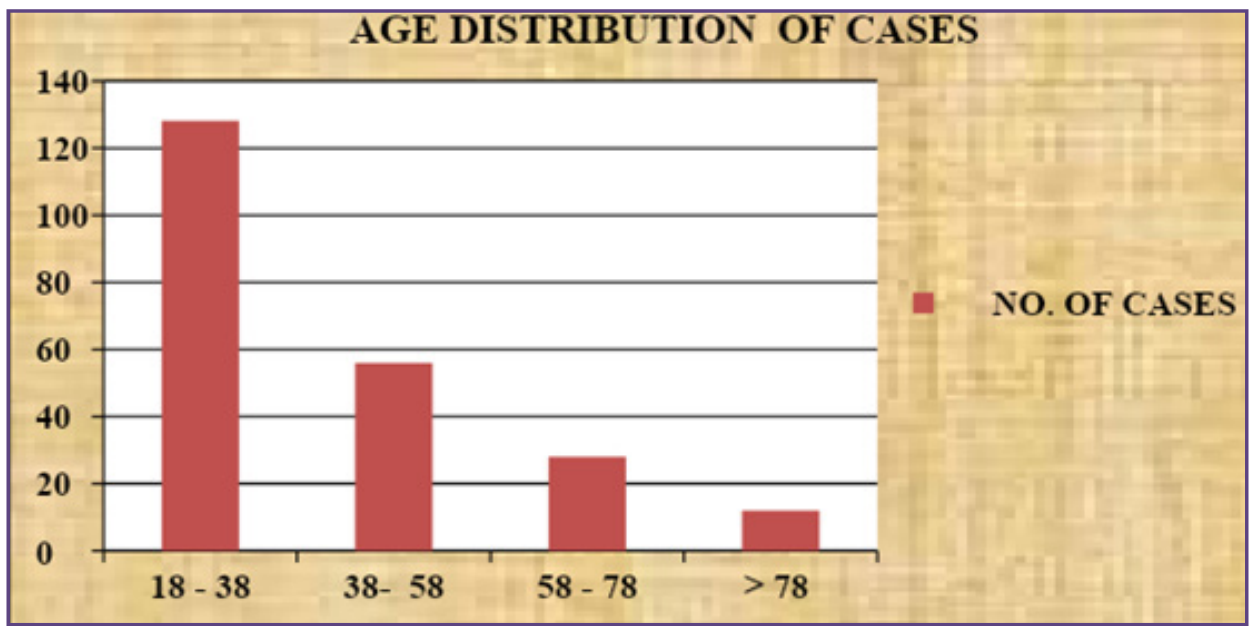

Fig. 1: Figure showing age distribution of cases.

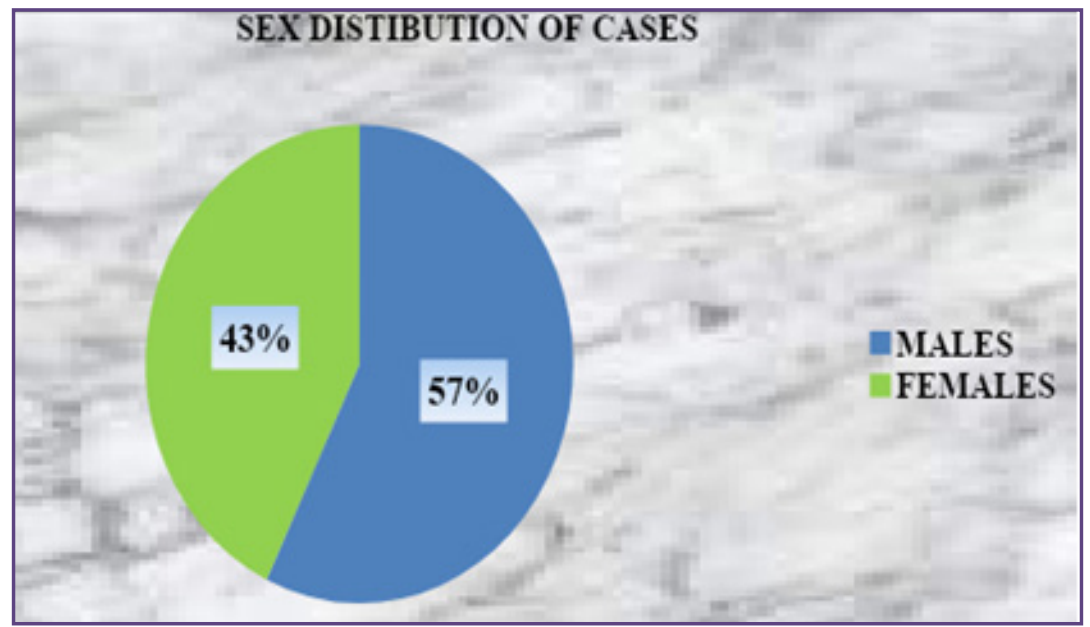

Fig. 2 : Figure showing sex distribution of cases.

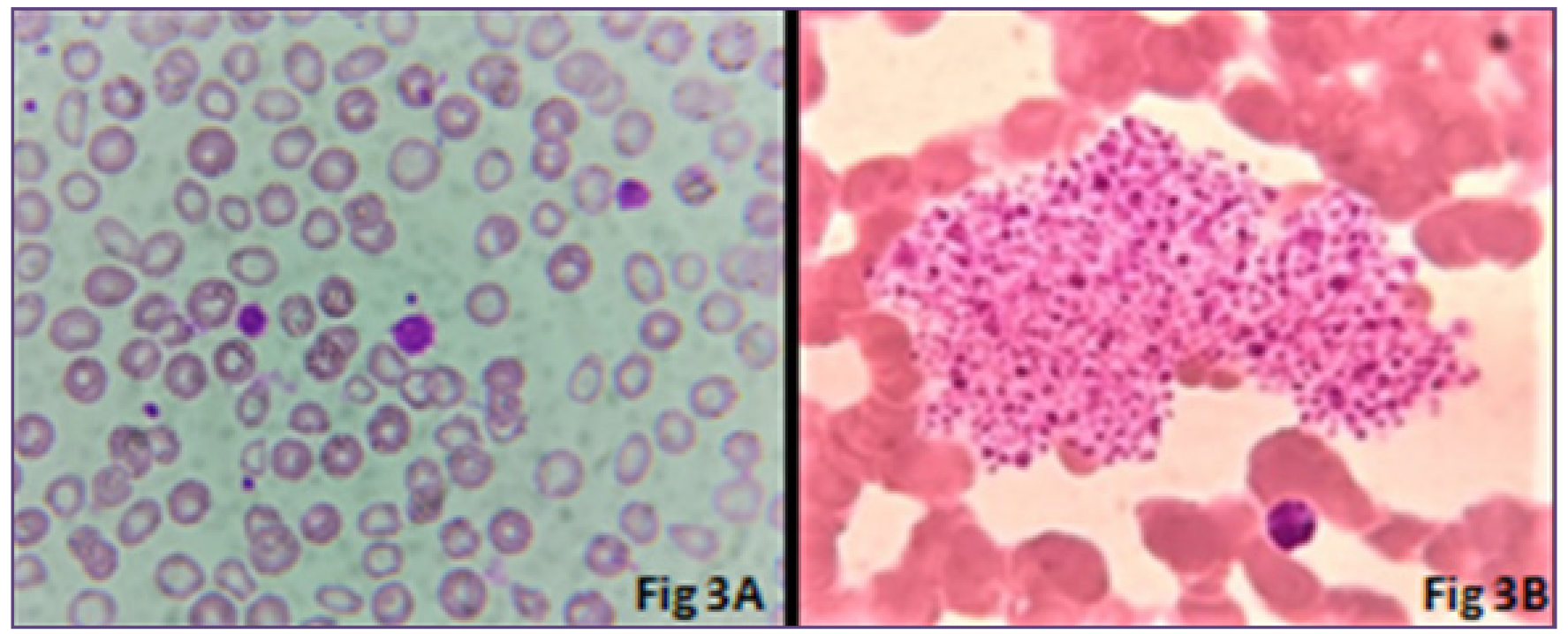

Fig. 3A- Giant platelets,3B- Platelet clump.(Leishman stain, x100 ). 


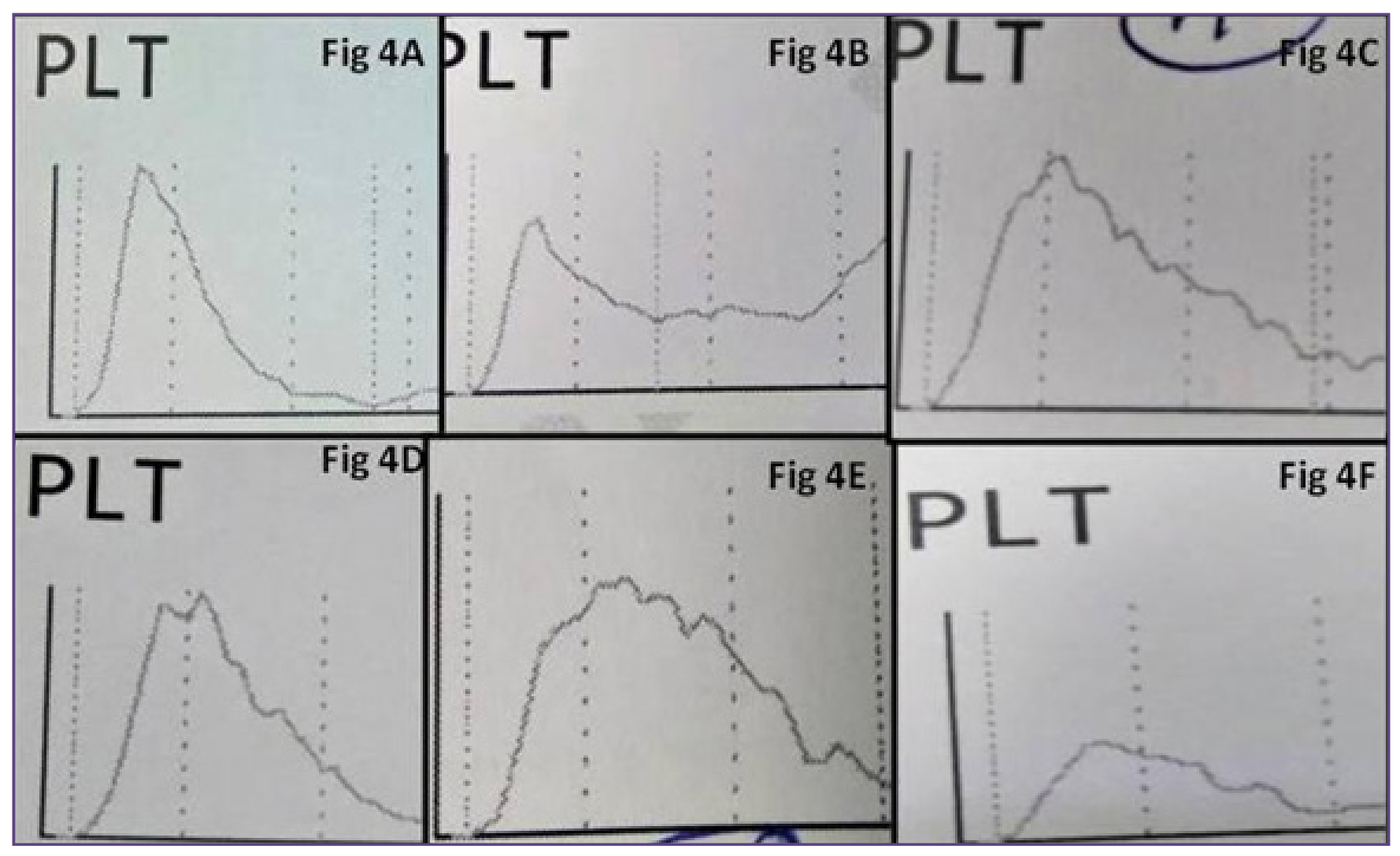

Fig. 4A- Normal curve, 4B-Curve not touching the baseline, 4C-Saw-tooth appearance , 4D- Bimodal , 4E- Broad base, 4FShort peak.

\section{Discussion}

It is a well known fact that the platelets play an important role in the clotting cascade and help in preventing bleeding. They form by budding from the cytoplasm of the megakaryocytes, their mother cells in the bone marrow. Even though, there are some ethnic variations, platelet count below $150 \times 10^{9} / \mathrm{L}$ is the standard definition of thrombocytopenia as accepted worldwide. ${ }^{[7,8]}$

Thrombocytopenia is a commonly encountered condition in clinical practice. The underlying mechanisms of thrombocytopenia can be broadly categorized as hyperdestructive causes, hypoproductive causes, causes due to abnormal pooling and EDTA induced thrombocytopenias. ${ }^{[8]}$ With the advent of automation in hematology, automated cell counters are now used all over the world to measure the various blood indices. The analyzers have the advantage of not only being quick but are also able to throw light on a wide variety of indices and minimize the inter-observer bias. ${ }^{[2,9,10]}$ The analyzers also display a plateletogram along with numerical indices which are often overlooked. ${ }^{[4]}$ Other than the routine platelet counts, which is the most commonly asked parameter, the other platelet indices like MPV [Mean platelet volume],
PCT [plateletcrit] and PDW [platelet distribution width] are also available in the analyzer readings. ${ }^{[10,11]}$

Majority of the thrombocytopenic cases in our study fell into the third decade of life, with the male to female ratio being 1.3:1, similar to the study done by Borkataky et al. ${ }^{[12]}$ This dominant age group could be attributed to the large load of viral infections in our area affecting young population working outdoors.

Thrombocytopeniacanbeeitherduetoperipheraldestruction (hyperdestructive thrombocytopenias) or due to inadequate production (hypoproliferative thrombocytopenias).The other causes being abnormal splenic sequestration of the platelets causing splenomegaly and EDTA induced thrombocytopenias ${ }^{[13]}$ Hyperdestructive thrombocytopenia category includes idiopathic thrombocytopenias, malaria, Kala-azar, dengue fever, renal diseases, cardiac diseases, sepsis and viral fevers. ${ }^{[12,14]}$ In our study distribution of the etiologies were similar to other studies by Reddy et al. ${ }^{[15]}$, Katti et al. ${ }^{[16]}$ and Numbenjapon et al. ${ }^{[17]}$ as shown in the results. Dengue cases predominated the hyperdestructive group as the study was done during the early monsoon which is the peak season for this entity. Hypoproductive group, included anemias, pancytopenias, acute leukemias 
and chronic lymphocytic leukemias (with marrow infiltration), post chemotherapy cases \& myelodysplastic syndromes. ${ }^{[18]}$ As most of our patients come from a rural background, it was no surprise that a higher percentage of cases fell into the anaemic etiology in the hypoproductive group.

Platelet clumping phenomenon is reflected in the form of multiple peaks on platelet histogram ${ }^{[17]}$. In our study, saw toothing of curve and curve not touching the baseline on the platelet histogram were seen. Only for these cases, normal platelet count was obtained from a fresh sample collected in heparin as an anticoagulant instead of EDTA and was run in the analyzer. This is a well known in-vitro phenomenon, induced at room temperature in EDTA anticoagulated blood and is postulated due to preformed EDTA-dependent antibody with dual reactivity against both the platelet glycoprotein IIb/IIIa complex and the neutrophil Fc gamma receptor III. It is a fairly common phenomenon seen 1 in 1000 normal adults. ${ }^{[19]}$

Immune Thrombocytopenic Purpura (ITP) is a condition where there is accelerated platelet destruction by autoantibodies including cold agglutinin type of $\mathrm{IgG}$, $\operatorname{IgM}$ and $\operatorname{IgA}$ with platelet surface antigens. This causes a compensatory increase in platelet production, as a result of which circulating platelets in patients with ITP are younger and have larger size causing the broad base in the platelet curve. ${ }^{[17,19,20]} \mathrm{A}$ significant number of cases showed curve with a broad base. Unrecognized pseudothrombocytopenia may result in unnecessary laboratory testing and unwarranted interventions by clinicians. Examination of a well-stained peripheral blood smear is mandatory for every case of thrombocytopenia to rule out platelet clumping (Pseudo-Thrombocytopenia). ${ }^{[21]}$

Inflammatory foci in the body lead to the activation of platelets, which induces morphological changes in them like change in shape from discoid to spherical and formation of pseudopodia. The activated platelets with pseudopodia formation can be of varying sizes, resulting in larger PDW values. The relationship between platelet and inflammation is mutual. Platelet promotes inflammatory progress and inflammation changes the platelet shape. As a result, PDW can be an important platelet marker that can reflect an inflammatory condition in some infectious diseases ${ }^{[22]}$ A few studies have also concluded that megakaryocytic hyperplasia was also responsible for PDW increase. ${ }^{[23]}$

\section{Conclusion}

An awareness regarding the variations in the platelet histogram like broad base, multiple peaks, curve not touching the baseline ensures a good correlation with its numerical parameters and underlying mechanisms of thrombocytopenia. With the era of automation having taken over in most of the laboratories, it is imperative to have knowledge about these simple but yet often overlooked graphical variations.

\section{Conflict of Interest}

All the authors declare that they have no conflict of interest of any sort pertaining to the article.

\section{References}

1. Lee GR, Foerster J, Lukens $\mathrm{J}$ et al: Wintrobes clinical hematology, in Diagnostic approach to the bleeding disorders, 12th ed. Lippincott Williams and Wilkins: 2009; pg 1277-91

2. Parveen S, Vimal M. Role of Platelet Indices in Differentiating Hypoproductive and Hyperdestructive Thrombocytopenia. Annals of Pathol Lab Med. 2017; 4(3): 288-91

3. Shah AR, Chaudhari SN, Shah MH, et al. Role of platelet parameters in diagnosing various clinical conditions. Natl J Med Res 2013; 3: 162-65

4. Khairkar PS, Pandey A, More S, Pandey M. Platelet Distribution Width (PDW) - A Rarely Studied Platelet Indice for Determining the Causes of Thrombocytopenia. Ann. Int. Med. Den. Res. 2016;2(4):193-97

5. Hamzullah K, Adnan M, Fazle B, Naila T, Ameezullah. Role of mean platelet volume (MPV), platelet distribution width (PDW) and platelet large cell ratio (PLCR) in diagnosis of hyperdestructive thrombocytopenia. Professional Med J 2019; 26(8):1266-71. DOI: 10.29309/ TPMJ/2019.26.08.3867

6. Negash M, Tsegaye A, Medhin AG. Diagnostic predictive value of platelet indices for discriminating hypo productive versus immune thrombocytopenia purpura in patients attending a tertiary care teaching hospital in Addis Ababa, Ethiopia. BMC Hematology 2016; 16:1-8.

7. Mala K.G, Bhandari B.J, Kittur S.K. Paramountcy of platelet parameters in thrombocytopenia- Our hospital experience. Indian J Pathol Oncol. 2018; 5(4): 558-62.

8. Gulati I, Kumar H, Sheth J, Dey I. Diagnostic implication of mean platelet volume in thrombocytopenia. Med J DY Patil Univ 2017; 10: 370-5.

9. Bashir AB, Saeed OK, Mohammed BA, and Ageep AK. Role of platelet indices in patients with dengue infection in red sea state, Sudan. International journal of science and research. 2015; 4(1): 1573-6

10. Amar RS, Sanjay NC, Menka HS. Role of platelet parameters in diagnosing various clinical conditions. National $\mathrm{j}$ med Res 2013; 3(2): 162-5.

11. Khaleel KJ, Ahmed AA, Alwash A, Anwar A. Platelet indices and their relations to platelet count in hypoproductive and hyper-destructive Thrombocytopenia. Karbala J. Med. 2014; 7(2): $1952-8$ 
12. Borkataky S, Jain R, Gupta R, Singh S, Krishnan G, Gupta $\mathrm{K}$, et al. Role of platelet volume indices in the differential diagnosis of thrombocytopenia: a simple and inexpensive method. Hematology 2009; 14: 182-6.

13. Kottke-Marchant K, Corcoran G. The laboratory diagnosis of platelet disorders: an algorithmic approach. Arch Pathol Lab Med. 2002; 126(2): 133-46

14. Elsewefy DA, Farweez BA,Ibrahim RR: Platelet indices: consideration in thrombocytopenia. Egyptian J Haematol 2014, 39: 134-8

15. Reddy RS, Phansalkar MD, Ramalakshmi PVB. Mean Platelet Volume (MPV) in Thrombocytopenia. J Cont Med A Dent. 2014; 2(2): 45-50.

16. Katti TV, Mhetre SC, Annigeri C. How far are the platelet indices mirror image of mechanism of thrombocytopeniamystery still remains? Int J Adv Med 2014; 1: 200-5.

17. Numbenjapon T, Mahapo N, Pornvipavee R, Sriswasdi C, Mongkonsritragoon W, Leelasiri A, et al. A prospective evaluation of normal mean platelet volume in discriminating hyperdestructive thrombocytopenia from hypoproductive thrombocytopenia. Int J Lab Hematol. 2008; 30(5): 408-14
18. Paula ES, Ronal JH. Platelets and megakaryocytes. In: Lee GR, Foerster J, Lukens J, Paraskevas F, Glader BE, Rodgers GM. (eds) Wintrobe's Clinical Hematology, 11th edn. Philadelphia, PA: Lippincott Williams and Wilkins, 2001; 615-42.

19. Thomas ETA, Bhagya S, Majeed A. Clinical Utility of Blood Cell Histogram Interpretation. J Clin Diagn Res. 2017; 11(9): OE01-OE04. doi:10.7860/JCDR/2017/28508.10620

20. Sahin C, Kırlı I, Sozen H, Canbek TD. EDTA-induced pseudothrombocytopenia in association with bladder cancer. BMJ Case Rep. 2014; 2014: bcr2014205130. Published 2014 Jun 20. doi:10.1136/bcr-2014-205130

21. Shabnam I, D S C, B C J. Ethylenediaminetetraacetic Acid (EDTA) - dependent pseudothrombocytopenia: a case report. J Clin Diagn Res. 2014; 8: FL03-4.

22. Karagoz B, Alacacioglu A, Bilgi O, Demirci H, Ozgun A, Akyol Erikci A et al. Platelet count and platelet distribution width increase in lung cancer patients. Anatolian Journal of Clinical Investigation. 2009; 3(1): 32-4.

23. Vagdatli E, Gounari E, Lazaridou E, Katsibourlia E, Tsikopoulou F, Labrianou I. Platelet distribution width: a simple, practical and specific marker of activation of coagulation. Hippokratia. 2010; 14(1): 28-32.

*Corresponding author:

Dr. Shubha. H.V., P-101, Vaishnavi Rathnam apartment, SM Road, Beside Triveni petrol bunk, Jalahalli cross, Bangalore, India-560057.

Phone: +919481421834

Email: drshubhahv@gmail.com

Financial or other Competing Interests: None. 